\title{
Critérios de Médicos Oncologistas para Encaminhamento Psicológico em Cuidados Paliativos
}

Oncology Medical Criteria for Psychologycal Referral in Palliative Care

Criterios de Médicos Oncólogos para Derivación Psicológica en Cuidados Paliativos

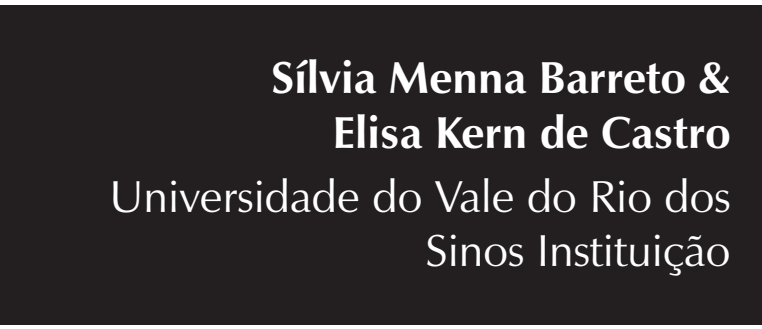

http://dx.doi.org/10.1590/1982-3703000202013 
Resumo: O estudo teve como objetivo conhecer a percepção dos médicos oncologistas acerca do sofrimento do paciente em cuidados paliativos e identificar critérios utilizados para encaminhamento desses pacientes para atendimento psicológico. Seis médicos foram entrevistados individualmente e suas falas submetidas à análise de conteúdo. Foram identificados dois eixos temáticos divididos em categorias: 1) Sofrimento: Tipos de sofrimento (psicológico, espiritual, físico e total); relação médico-paciente; suporte social; importância da Psicologia; e 2) Encaminhamento para a Psicologia: critérios utilizados; obstáculos para o encaminhamento. Conclui-se que os médicos reconhecem as necessidades psicológicas do paciente em cuidados paliativos e a necessidade de trabalho interdisciplinar. Entretanto, parece não haver critérios objetivos para o encaminhamento desses pacientes para atendimento psicológico, sendo necessário refletir e mudar a forma de encaminhamento e atuação em equipe.

Palavras-chave: Cuidados paliativos. Interdisciplinaridade. Sofrimento.

Abstract: The present study aimed to understand the perceptions of oncologists about the patient's suffering in palliative care and to identify criteria for referral of patients to psychological treatment. Six physicians were interviewed individually and their statements were submitted to content analysis. The themes identified were divided into two categories: 1) Suffering: Types of distress (psychological, spiritual, physical and total), doctor-patient relationship, social support, importance of psychology; and 2) Referral to Psychology: criteria used; obstacles for routing. We conclude that physicians recognize the psychological needs of patients in palliative care and the need for interdisciplinary work. However, there seem to be no objective criteria for the referral of these patients to psychological assistance, being necessary to reflect and change the forwarding and team work.

Keywords: Palliative care. Interdisciplinarity. Suffering.

Resumen: El objetivo del estudio fue conocer la percepción de los oncólogos acerca del sufrimiento del paciente en cuidados paliativos e identificar los criterios para la derivación de dichos pacientes hacia el tratamiento psicológico. Se entrevistaron individualmente a seis médicos y sus discursos fueron sometidos al análisis de contenido. Los temas identificados fueron divididos en dos categorías: 1) Sufrimiento: Tipos de angustia (psicológica, espiritual, física y total), relación médico-paciente, apoyo social, importancia de la psicología, y 2) Derivación para la psicología: criterios utilizados, obstáculos para la derivación. Se concluye que los médicos reconocen las necesidades psicológicas del paciente en cuidados paliativos y la necesidad de un trabajo interdisciplinario. Sin embargo, no parece haber criterios objetivos para la derivación de estos pacientes para atendimiento psicológico, y, así, se hace necesario discutir y cambiar la forma de derivación y el trabajo en equipo.

Palabras-clave: Cuidados paliativos. Interdisciplinaridad. Sufrimiento.

\section{Introdução}

O advento do movimento hospice ${ }^{1}$, na segunda metade do século XX, tornou Cicely Saunders precursora da filosofia dos cuidados paliativos (Guimarães, 2009). Saunders, ao dedicar-se aos pacientes moribundos na Inglaterra em meados do século XX, criou o termo dor total para mostrar que o sofrimento do doente sem possibilidade de tratamento curativo é físico mas também psicológico, social e espiritual
(Figueiredo, 2008). A partir de então começou a crescer o interesse pelo sofrimento e pela necessidade de melhora da qualidade de vida desses pacientes, além do direito de terem uma morte digna sem adiamentos e prolongamentos desnecessários.

Os cuidados paliativos, portanto, podem ser caracterizados pela assistência promovida por uma equipe de saúde com o objetivo de melhorar qualidade de vida do paciente 
e de seus familiares frente a uma doença que ameaça a vida (Figueiredo, 2008; Menezes, 2004). Isso se dá através da prevenção, da identificação precoce e do alívio do sofrimento do paciente, da avaliação e do tratamento da dor e demais sintomas físicos, sociais, psicológicos e espirituais que possam surgir. Portanto, essa proposta é construída e fundada em um corpo teórico baseado nas necessidades específicas do doente, conjugada a valores humanísticos, em especial à compaixão (Menezes, 2004).

Na assistência ao paciente em cuidados paliativos, a presença da dor pode ser um empecilho para a construção de uma assistência que contemple a totalidade do indivíduo (Menezes, 2004). Porém, uma vez que o sofrimento do indivíduo pode ser expresso sob diferentes aspectos - físico, psicológico, social, econômico -, igualmente devem ser as esferas do cuidado dispensado aos pacientes sob cuidados paliativos (Silva \& Hortale, 2006). Alude-se ao papel desempenhado pela equipe médica no que se refere ao controle de sintomas, em especial, à dor intensa. Essa acomete $75 \%$ dos pacientes com câncer avançado, interferindo na sua qualidade de vida e sendo considerada, conforme a Organização Mundial da Saúde (OMS), uma emergência médica mundial (Salamonde, Verçosa, Barrucand \& Costa, 2006).

O sofrimento emocional é parte importante do sofrimento do paciente oncológico em cuidados paliativos tendo em vista a menor perspectiva de vida, bem como os efeitos da própria doença e tratamento. Nessa circunstância, tanto os pacientes como seus familiares podem manifestar a necessidade de atendimento psicológico (Almonacid, Moreno \& Lluch, 2009). Segundo Borges et al. (2006), há poucas pesquisas referentes à análise de intervenções psicológicas no processo de morrer e aquelas existentes sugerem que o suporte psicológico deve ser baseado nos princípios dos cuidados paliativos, da qualidade de vida e do controle da dor.

Desse modo, a equipe deveria oferecer uma atenção integral ao paciente, considerando a dimensão biopsicossocial e espiritual, aspecto que vem ao encontro da filosofia dos cuidados paliativos. Entretanto, essa interdisciplinaridade não está estabelecida, é preciso "construí-la".
Cabe à equipe que compartilha dessa visão uma reformulação dos saberes, o que resultará na reorganização da equipe de saúde (Riba \& Dias, 2009). Para González e Branco (2012, p. 253), a capacidade de diálogo entre diferentes profissionais e o respeito aos diferentes pontos de vista propicia uma boa relação e comunicação entre a equipe, pois "comunicar-se tem a ver com emocionar-se e saber lidar com tais emoções". Assim, o próprio SUS hoje reconhece a necessidade de mudar a forma como as equipes se relacionam, resgatando a parte humana no cuidado ao paciente. Nesse sentido, o psicólogo participaria de forma igualitária com os outros profissionais, com autonomia para a realização do seu trabalho dentro da equipe, mas hoje ainda não é o que ocorre na rede de saúde pública brasileira (Böing \& Crepaldi, 2010).

Nota-se, assim, que o movimento dos cuidados paliativos retirou o indivíduo diagnosticado como fora de possibilidades terapêuticas de um plano marginal, no qual não havia espaço para a expressão de seus desejos e sentimentos ou, ainda, livre exercício de sua autonomia (Riba \& Dias, 2009). Nessa modalidade de atendimento, a ênfase na dignidade do doente é central. Então, mais do que auxiliá-lo nesse processo, que tem como resultado final a morte, deve-se ajudá-lo a viver com qualidade no tempo restante de sua vida. Desse modo, evidencia-se o caráter diferenciado dessa modalidade de assistência, que se esforça para oferecer um atendimento humanizado a pacientes que, outrora, em algum momento de sua vida, foram informados que "não existia mais nada a fazer".

Assim, tendo em vista a relevância do cuidado integral ao paciente em cuidados paliativos, esse estudo se propôs conhecer a percepção de médicos oncologistas acerca das necessidades psicológicas do paciente em cuidados paliativos e, também, buscou identificar os critérios por eles utilizados para encaminhamento desses pacientes ao atendimento psicológico.

\section{Método}

\section{Delineamento}

Trata-se de um estudo qualitativo, de caráter exploratório. $\mathrm{Na}$ abordagem qualitativa, o pesquisador utiliza-se da interpretação dos 
dados, além de ver os fenômenos sociais de modo holístico, oferecendo uma visão ampla do universo em estudo (Creswell, 2007).

Participantes

Seis médicos oncologistas (duas mulheres e seis homens), com experiência profissional que variou de 12 a 39 anos e idade entre 35 e 64 anos, selecionados por conveniência. Dois médicos não aceitaram participar do estudo alegando falta de tempo disponível para a entrevista.

Instrumentos

Entrevista semiestruturada composta por quatro questões norteadoras, a saber: 1 - Conte-me sobre a sua experiência em atendimento a pacientes sob cuidados paliativos; 2 - Qual a sua percepção sobre a relação médico-paciente nesses casos ?; 3 - Qual a sua percepção sobre o sofrimento psicológico desses pacientes? Conte um caso em que tenha observado esse sofrimento; 4 - Quais critérios você utiliza para encaminhar o paciente ao psicólogo nos casos de cuidados paliativos? Conte-me um caso em que o encaminhamento foi realizado.
Procedimentos de coleta de dados e éticos

A coleta ocorreu de forma individual nos locais de trabalho dos participantes. O projeto foi aprovado pelo Comitê de Ética da [nome da instituição omitido para evitar identificação] (N. CEP 11/042). O convite para participação na pesquisa foi realizado pessoalmente pela primeira autora em quatro casos e por e-mail em outros dois. Os participantes, ao final do estudo, receberam um relatório com os principais resultados da pesquisa.

Análise dos dados

As entrevistas foram gravadas, transcritas e submetidas à análise de conteúdo seguindo os passos de Moraes (1999). A análise ocorreu em três partes: 1) transcrição das entrevistas; 2) demarcação das unidades de sentido; e 3) geração de categorias temáticas, sendo essas criadas a partir dos relatos dos médicos. O tempo de duração da entrevista variou entre $15 \mathrm{~min}$ e $30 \mathrm{~min}$.

\section{Resultados e discussão}

A partir do discurso dos participantes foram identificados dois grandes eixos temáticos que, por sua vez, deram origem às seguintes categorias e subcategorias (Tabela 1).

Tabela 1. Descrição dos temas, categorias e subcategorias

\begin{tabular}{|c|c|c|}
\hline EIXOS TEMÁTICOS & CATEGORIAS & SUBCATEGORIAS \\
\hline & Sofrimento & $\begin{array}{l}\text { Psicológico (do paciente, da família e do } \\
\text { médico) }\end{array}$ \\
\hline & & Espiritual \\
\hline & & Físico \\
\hline & & Total \\
\hline \multirow[t]{3}{*}{ SOFRIMENTO } & $\begin{array}{l}\text { A importância da relação } \\
\text { médico-paciente }\end{array}$ & $\begin{array}{l}\text { A influência da equipe/familiares na relação } \\
\text { médico-paciente }\end{array}$ \\
\hline & Critérios utilizados & Pelo médico \\
\hline & & Por qualquer profissional da equipe \\
\hline \multirow{4}{*}{$\begin{array}{l}\text { PROCESSO DE ENCAMINHAMENTO } \\
\text { PARA O SERVIÇO DE PSICOLOGIA }\end{array}$} & Obstáculos para & Operacional \\
\hline & $\begin{array}{l}\text { encaminhamento à } \\
\text { Psicologia }\end{array}$ & \\
\hline & & $\begin{array}{l}\text { Modo que o profissional realiza o } \\
\text { encaminhamento }\end{array}$ \\
\hline & & $\begin{array}{l}\text { Critérios imprecisos de encaminhamento } \\
\text { para Psicologia e Psiquiatria }\end{array}$ \\
\hline
\end{tabular}




\section{Eixo temático I: Sofrimento}

Aborda as dimensões de sofrimento do paciente em cuidados paliativos, bem como aspectos relacionais (família, equipe, suporte social) e a importância da Psicologia para tratar desse sofrimento.

Sofrimento: Psicológico, espiritual, físico e total

A expressão psicológica, frente à terminalidade do paciente com câncer pode adquirir contornos diferentes, conforme a etapa do ciclo vital do indivíduo. Nesse sentido, parece que pacientes idosos e pacientes jovens, de acordo com o médico 1, tendem a encarar o processo de terminalidade de modo diferente, tendo em vista o tempo de vida usufruído: "Geralmente a pessoa mais idosa já viveu muito, já teve os seus filhos, já teve a sua família, já teve... realizou os seus sonhos e tá aguardando"2. No entanto, é importante reconhecer que pacientes idosos também experimentam o medo da morte, pois essa é uma experiência individual que remete ao desconhecido (Borges et al., 2006). Nesse sentido, a concepção do velho como um sábio, que está preparado e apenas aguardando pela morte não corresponde à realidade (Borges et al., 2006). Por outro lado, é possível que os pacientes jovens apresentem maior relutância em aceitar a morte, em função da perspectiva de futuro, segundo o mesmo médico: "A pessoa jovem é meio relutante, ela tem muito o que viver (...)" (médico 1). A resistência frente à morte do paciente jovem pode ter relação com as expectativas em relação ao futuro. Desse modo, a morte acaba sendo interpretada como uma interrupção no seu ciclo biológico, gerando sentimentos de impotência, de frustração, de tristeza, de dor e de angústia (Alarcão, Carvalho \& Pelloso, 2008).

Para os médicos 3 e 5, o sofrimento causado pela terminalidade tem relação com a dificuldade de aceitação da finitude: "Tem gente que não consegue tocar no assunto, a negação do fenômeno morte é tão grande que... que chega uma hora dessas... por mais óbvio, por mais sereno que tudo tenha sido, choca" (médico 5). Para Mendes, Lustosa e Andrade (2009), o tempo de permanência no estágio de negação depende de diversos fatores, tais como: personalidade, apoio familiar e social, cultura, idade, forma de comunicação do diagnóstico, entre outros. O paciente, ainda, pode expressar o seu sofrimento através da projeção da raiva na equipe, conforme relata o médico 6: “(...) é mais fácil eu lutar... eu... eu ficar brabo com... o patologista, com o gineco[logista] ou até com o oncologista dele se... do que com a doença que é uma coisa que eu não consigo ter controle". Nesse sentido, a raiva pode estar relacionada a sentimentos de impotência, sendo projetada no ambiente sem uma razão plausível (Kubler-Ross, 2008).

Em alguns casos, o sofrimento psicológico pode ser influenciado por distintos fatores, tais como a espiritualidade e o balanço da vida (médico 2). A espiritualidade é percebida como a capacidade de transcender a situação da doença e finitude: "(...) depende muito da espiritualidade do paciente, mas não quer dizer assim ó, tal fé religiosa ou... se a pessoa é mais espiritualizada ou não. Tem muito a ver como que ela consegue transcender, né (...)" (médico 2). A espiritualidade pode auxiliar o paciente no enfrentamento da dor e do sofrimento, porém os profissionais podem encontrar dificuldade para lidar com essa dimensão (Riba \& Dias, 2009), conforme relata o médico 4: "a situação espiritual que as pessoas pouco valorizam é de uma grandiosidade, é de uma importância... ímpar, né? Você não falar sobre isso, você não... é... é... liberar que a pessoa fale sobre isso é de uma... de uma... incompetência relacional muito grande (...)".

O balanço de vida suscitado pela proximidade da morte pode gerar no paciente sentimentos de culpa, bem como temor em relação ao futuro: "Ele tava morrendo e ele sabia que tava morrendo e ele disse assim: 'Eu não tenho problema de morrer, mas doutora, eu fiz tão mal pra tanta gente que eu sei que eu não vou ser absolvido agora, né? (...)'”' (médico 2). Por outro lado, a impossibilidade de realizar esse balanço parece causar sofrimento para o paciente, conforme assinala o médico 4: (...) 'O que que eu deixei de fazer? (...) O que eu podia ter feito que eu não fiz nesse tempo que eu tava aqui?' (...) Alguns conseguem verbalizar isso claramente, outros não verbalizam. Até porque existe, eventualmente, um paternalismo tão grande em cima dele, (...) existe uma conspiração do silêncio, né?" Considerando que o sofrimento causado pelo 
balanço da vida e proximidade da morte é inevitável, é fundamental o acolhimento e a escuta do paciente em cuidados paliativos a fim de amenizar o seu sofrimento e dor total (Borges et al., 2006; Figueiredo, 2008; Kovács, 2007).

Embora a espiritualidade auxilie no processo de terminalidade, sentimentos de insegurança face ao desconhecido podem surgir, conforme o médico 4: "A gente tá perdendo a vida, a gente não sabe o que vai encontrar depois, quer coisa mais enlouquecida do que isso? Por mais que você seja superespiritualizado, tenha a sua religião muito presente (...) aceite o inevitável... não tem jeito". Assim, é compreensível o sofrimento frente à morte, o que, segundo Rezende (2000), pode conduzi-lo à busca de recursos, de elementos e de palavras que possam dar um sentido para esse fato definitivamente desconhecido e desintegrado de tudo: o inexorável fim.

Desse modo, o sofrimento parece refletir-se em todas as dimensões da vida do indivíduo: “(...) o sofrimento mexe com todas as dimensões, né?, física, social, psicológica, a espiritual, né? (...) o sofrimento psicológico faz parte da dimensão de sofrimento de outros tantos sofrimentos" (médico 4). Conforme esse médico, o sofrimento psicológico não poderia ser considerado de forma individual, o que remete ao conceito de dor total, desenvolvido por Cicely Saunders, entendido como o estado no qual a dor física conjuga-se à dor psíquica, espiritual e social (Menezes, 2004). Contudo, o médico 4 parece ampliar ainda mais essa visão, ao afirmar que todos os sintomas contêm todos os sofrimentos: "(...) o que eu vejo, o sofrimento é que ele não é um sofrimento psicológico. É um sofrimento total. (...) eu, eu acho que existe ansiedade total, a fadiga total, o vômito, náusea total, porque é tudo junto". Diante disso, haveria um ponto de convergência entre as dimensões de sofrimento, de modo que cada uma delas abarcasse as demais.

\section{A importância da relação médico-paciente}

A natureza da relação clínica médico-paciente surgiu na fala dos entrevistados numa tentativa de se entender o sofrimento do paciente. Dentre os fatores que contribuem para o prejuízo dessa relação encontram-se os problemas de comunicação enfrentados pelo profissional. Para o médico 1, o paciente parece apresentar maior sofrimento quando não é preparado adequadamente sobre o diagnóstico e prognóstico: "Mas foi muito difícil essa... esse impacto inicial de dar a notícia porque ele não foi preparado desde o início (...) Pelo nosso... a outra equipe que o assistiu". É possível que a dificuldade de comunicação do profissional leve ao abandono do paciente na fase terminal da doença: “(...) quando chega na fase terminal o colega simplesmente abandona o paciente porque não soube lidar desde o início, não soube conversar desde o início sobre a doença" (médico 1). Pode-se compreender a crítica a outros profissionais da mesma categoria como uma forma de projeção, o que, talvez, sugira receio de o médico falar sobre si mesmo. Nesse sentido, comunicar más notícias pode causar grande estresse não só nos pacientes, mas também nos médicos, que muitas vezes procuram evitar essa tarefa através de técnicas de distanciamento. Esse comportamento pode produzir sofrimento para o paciente, visto que conduz a um sentimento de insegurança em relação à doença, ao prognóstico e ao médico (Riba \& Juver, 2009). Além disso, o paciente frequentemente manifesta o desejo de conhecer a verdade acerca de sua condição. Evidencia-se, assim, que a natureza da má notícia não reduz o desejo de informação do paciente, além de ser fundamental para a tomada de decisão e para o sentido de esperança do mesmo (Nogueira Filho, 2010). Diante disso, a presença de um laço afetivo com o paciente e a família parece facilitar a comunicação de más notícias, fazendo com que os envolvidos as percebam como uma forma de cuidado, de acordo com o médico 2: “(...) sempre que tu conseguir desenvolver um laço afetivo com o paciente e com a família, esse momento é mais fácil (...) Porque... eles, todos estão extremamente fragilizados e tu vai ter que dizer coisas que eles não querem ouvir, né? (....)". O reconhecimento desse aspecto implica em uma nova compreensão do profissional, ou seja, de que não há possibilidade de contato humano sem a perspectiva de formação de vínculo (Ferreira \& Queiroz, 2010).

Parece relevante, também, a verificação da informação dada ao paciente, tendo em vista sua mutabilidade, que pode gerar maior 
sofrimento para ele: “(...) Essa... essa coisa de buscar (...) sabe, verificar a integridade dessa informação, que ela tá muito mutável (...)" (médico 5). Essa conduta pode favorecer a redução da incerteza da situação vivida pelo doente, contribuir para o fortalecimento da relação médico-paciente, bem como oferecer uma orientação ao enfermo e sua família (Menezes, 2004). Por outro lado, é possível que a falta de confiança na capacidade técnica do médico e uma postura arrogante interfiram na relação, levando à perda do vínculo e, consequentemente, ao sofrimento do paciente (médico 4): "basicamente... paciente tem que ter certeza de que você sabe o que tá fazendo (...) perdeu a confiança não tem relação médico-paciente nenhuma (...) Ninguém gosta de ser maltratado. Então, assim, 'quem é você pra me maltratar, ainda mais eu que to nessa situação de sofrimento, né?". Nesse sentido, oferecer orientação ao paciente sobre os efeitos colaterais possíveis, bem como sobre as formas de manejá-los já no momento de proposição do tratamento pode contribuir para maior segurança dele (Osanai, 2004).

Eixo temático Il: encaminhamento para a Psicologia

Serão abordados, a seguir, os critérios utilizados pelos médicos entrevistados, bem como os obstáculos que eles percebem para o encaminhamento do paciente em cuidados paliativos à Psicologia.

Critérios de encaminhamento para a Psicologia

Observam-se diversos trabalhos acerca do encaminhamento de pacientes ao psicólogo no âmbito escolar (Mattos, 2005; Zibetti, Souza \& Queiroz, 2010), porém no contexto hospitalar o tema é praticamente inexistente. Analisando-se as falas dos médicos, verificou-se que não é comum a presença de um psicólogo como parte da equipe, e distintos aspectos conduzem o profissional a realizar a solicitação da assistência psicológica. A presença de sintomas depressivos parece despertar a atenção de alguns médicos, que geram o encaminhamento: "(...) quando a gente vê que o paciente entra em desespero, em depressão, raiva, qualquer sintoma que nos surja como sinal de alerta (...) esse paciente, que eu falei anteriormente, a Psicologia teve presente no caso e ela foi chamada porque ele queria se matar (...)" (médico 1).

Os sintomas depressivos, segundo Diniz etal. (2006), podem ser considerados frequentes em pacientes sob cuidados paliativos. Entretanto, para o médico 1 , o manejo psicológico parece ser priorizado, quando comparado à indicação farmacológica: "O que nós consideramos ali no... onde a gente trabalha é que quanto menos medicação a gente usar, a parte psíquica, melhor. Então, quanto mais manejo psicológico, melhor pro paciente". Verifica-se, portanto, a valorização do manejo psicológico, considerado pelo médico 1 a melhor alternativa para o paciente, pois, conforme Riba e Dias (2009), possibilita voltar o olhar para a angústia dele, buscando auxiliá-lo a encontrar possibilidades para lidar de modo mais satisfatório com seu sofrimento. Além disso, pacientes que apresentam dificuldades para enfrentar a situação parecem ter uma indicação objetiva de atendimento psicológico: “(...) têm várias situações, assim, que o paciente demonstra... que não tá tolerando, né?, a ideia de terminalidade, a sensação de finitude e tal e aí começa com um sofrimento psicológico muito intenso (...)" (médico 2).

Outro critério que parece conduzir ao encaminhamento para a Psicologia é a dificuldade apresentada pelo paciente de abordar questões de ordem prática oriundas de sua morte iminente com familiares e amigos, conforme aponta o médico 1: "Então isso é uma coisa importante que tem que também abordar com o paciente: olha, tu vai falecer, mas tu é chefe de família, tem que ver com quem vão ficar os teus bens, então essas coisas têm que definir também (...)". A dificuldade do paciente de abordar esses aspectos pode estar associada à dificuldade de aceitação da finitude e à preocupação em relação ao futuro de seus entes queridos (filhos, cônjuge etc.), que ficarão sem a sua companhia. Nesse sentido, falar sobre essas questões implica em recordar a proximidade da própria morte, fato que talvez se deseja negar ou evitar.

O encaminhamento para o psicólogo pode ainda ocorrer frente à dificuldade de o próprio médico lidar com a situação: "é, quando a gente não consegue, ah... nós próprios 
frente a um paciente, manejar isso aí... a gente precisa de mais apoio (...)" (médico 1); "Graças a Deus eu sempre tive noção das minhas limitações como médico, como cirurgião, como ser humano... eu sempre vi (...)...eu... eu não posso ir além, porque eu não entendo disso aqui. Então, esse foi o critério que eu sempre usei" (médico 3). Silva e Ayres (2010) destacam que os estudantes de Medicina e os médicos não são treinados, pela ênfase biológica associada à prática, de expressar e de escutar a dimensão da intersubjetividade, além de acolher o sofrimento humano, sendo ensinados a encobrir a dor do outro e a sua. Desse modo, torna-se imperativo o desenvolvimento de habilidades para lidar com a dimensão humana do paciente, bem como com as próprias emoções.

Além disso, alguns profissionais parecem adotar um critério preventivo de encaminhamento ao psicólogo em situação de terminalidade: "Então, como é que, em sã consciência, eu faço isso (prescrição farmacológica) e vou deixar pra chamar a Psicologia quando eu tenho um familiar berrando no corredor, quando eu tenho um paciente que tá quase catatônico e não come, sabe?" (médico 5). É possível, igualmente, que o encaminhamento seja destinado aos familiares, que apresentam diferentes reações diante da iminência da morte do paciente, conforme os médicos $1 \mathrm{e}$ 4. Assinala-se que a fala do médico 4 refere-se ao encaminhamento realizado no âmbito da assistência domiciliar, geralmente, para os familiares: "Família não tá conseguindo elaborar luto, então, né?, tá fazendo todas as... as... as etapas que a gente já conhece, né?, de abandono, então superproteção, enfim (....)" (médico 4). Nessas circunstâncias, em que a dor pela perda iminente do ente querido começa a se fazer presente, o psicólogo depara-se com situações de luto antecipado, conforme assinalam os médicos. Segundo Silva (2003), o profissional que trabalha com esse tipo de situação deve ressaltar os benefícios, como: maior tempo para se preparar e realizar uma boa despedida, além de poder resolver (se for o caso) algum conflito pendente. Nesse sentido, a atuação do psicólogo assume um caráter preventivo, contribuindo para evitar um luto complicado dos familiares no futuro.
Obstáculos para encaminhamento à Psicologia

Os médicos entrevistados referiram diversos obstáculos de ordem prática e de ordem de relações de trabalho para encaminhamento à Psicologia, tais como: insuficiência de profissionais nas instituições, o modo como o médico realiza o encaminhamento e o desconhecimento sobre quando e por que encaminhar o paciente/família para a Psicologia e para a Psiquiatria. Nesse sentido, a imprecisão de critérios pode ser considerada um obstáculo, visto que impossibilita a realização de um encaminhamento adequado.

O apoio psicológico parece ser uma prática comum tanto à Psiquiatria como à Psicologia para o médico 2: "(...) vamos colocar, primeiro, num lugar só a Psiquiatria e a Psicologia, eu diria, assim, o apoio psicológico, né?" A visão de que o paciente se beneficia de um diálogo com o psicólogo ou com o psiquiatra é evidente, porém o papel do psiquiatra parece mais bem definido no que se refere à indicação farmacológica: "Quando eu sinto que o paciente tá com um sofrimento, né?, que ele poderia se beneficiar de conversar com alguém ou de ser medicado eu chamo... eu sempre proponho pro paciente, né? E aí, assim, normalmente, quando eu acho que $o$ paciente vai se beneficiar de medicação eu chamo o psiquiatra" (médico 2).

Além disso, eventualmente é possível que o paciente apresente necessidade de ter um atendimento apenas psicoterápico, sendo desnecessária a indicação farmacológica. Nesse caso, o profissional pode abster-se de escolher o profissional a quem encaminhar, permitindo que o paciente escolha qual profissional - psicólogo ou psiquiatra - deseja consultar: "Às vezes a gente sente que a pessoa não precisa de medicação, ela precisa tempo pra conversar (...) E, às vezes, o paciente diz 'Não, eu não quero um psiquiatra, eu prefiro um psicólogo', ou diz 'Não, eu não quero um psicólogo (...) um psiquiatra', né? Então, pra mim, é indiferente, se eu acho que não precisa de medicação, pra mim é indiferente" (médico 2).

O modo como o profissional realiza o encaminhamento pode influenciar na adesão do paciente ao tratamento, configurando-se, 
igualmente, em um obstáculo, de acordo com alguns entrevistados: "Eu acho que não propor, não comentar sobre isso, né?, e... e... e não tentar superar a dificuldade, porque... aquela coisa: O senhor quer uma psicóloga?, 'Humm, eu converso com o senhor', 'Não, a minha filha vem aqui, ela conversa muito comigo, eu tenho com quem conversar'... eu disse assim: É psicólogo, não é conversador (...) Então a ideia é que o apoio psicológico é alguém que vai vir me sugerir coisas ou que é só pra conversar, mas que não vai resolver nada" (médico 5).

Para o médico, a tarefa do encaminhamento psicológico requer paciência, disposição e conhecimento sobre a prática do psicólogo, pois ele poderá esclarecer também os benefícios desse acompanhamento durante essa difícil etapa. Essa postura parece conduzir o paciente à revisão de seus conceitos, refletindo-se numa melhor adaptação à doença e adesão ao tratamento: "(...) Quando se traz isso, 'Não, mas doutor, como é que é o negócio, então quer dizer que se tiver uma pessoa dessa, um apoio desse, lá no fim pode ser menos sofrido?', eu disse: Pode... pra mente, pros sentimentos pode, ou pode ser sofrido de uma maneira... ã... ã... mais adequada... mais, mais, mais compatível com aquilo ali (...)Então, é um trabalho continuado, né?, mas que vale a pena, porque lá no final vale muito a pena, com certeza" (médico 5).

Assim, a forma de encaminhamento que o médico faz ao paciente irá refletir seu modo de pensar sobre o trabalho do psicólogo e demonstrará, ou não, ao paciente, o valor que ele atribui para esse trabalho: “(...) essa oferecida tem que ser uma oferecida... embasada. Não é só: A senhora quer um atendimento psicológico? Acha que tá precisando? Não, não... ok! Vamos pra próxima. Então agora vamos falar de radioterapia, sabe? Como se oferece um menu de coisas (...) Ah! Gelo e limão na coca-cola? 'Não, não, não, sem gelo'. Tá tudo bem e fica assim e ninguém discute essa parte" (médico 5).

É possível, ainda, que o psicólogo seja solicitado, independentemente da vontade do paciente, quando identificadas dificuldades de adaptação à situação: “(...) a gente tá tendo (...) identificando, claramente, que aquilo tá prejudicando o paciente de alguma forma. A gente, mesmo que o paciente não queira, chama o psicólogo e diz pro paciente claramente: Olha, eu preciso, pra me ajudar numa avaliação psicológica" (médico 6).

Por último, destaca-se a insuficiência de psicólogos dentro das instituições de saúde, o que, para o médico 4, parece configurar-se em obstáculo para uma assistência integral ao paciente em cuidados paliativos: "Todos deveriam ter atendimento psicológico). Eu só não consigo fazer isso porque eu não tenho profissional suficiente (...) nas avaliações que eu fiz eu precisava ter o mesmo número de psicólogas que eu tenho de assistente social. E eu tenho muito mais assistente social e eu não sei por quê" (médico 4).

Assim, todos esses obstáculos remetem ao tema da interdisciplinaridade. Para Matos, Pires e Campos (2009), o trabalho interdisciplinar implica novas formas de relacionamento, tanto no que se refere à hierarquia institucional, à gestão, à divisão e à organização do trabalho, como no que se refere às relações que os trabalhadores estabelecem entre si e com os usuários do serviço. Embora os médicos valorizem a prática interdisciplinar, nota-se certo desconhecimento quanto ao papel desempenhado pela Psicologia, refletido na imprecisão de critérios de encaminhamento. Diante disso, a comunicação entre os agentes da equipe se faz fundamental, visto que oportuniza a articulação das ações, a coordenação, a integração dos saberes e a interação dos agentes por meio da mediação simbólica da linguagem (Peduzzi, 2001). Enfatiza-se esse aspecto pois o desconhecimento ou, ainda, a vaga ideia do que a Psicologia representa pode levá-la a ser vista como uma parte separada do restante das ciências da equipe, não sendo completamente aproveitada pelos profissionais (Moré, Crepaldi, Queiroz, Wendt \& Cardoso, 2004).

No momento em que o médico compreende a função do psicólogo, ele se capacita para esclarecer possíveis dúvidas do paciente e faz um encaminhamento com mais convicção da sua necessidade. Essa conduta requer a superação da visão biologicista, que reduz a complexidade do indivíduo ao negar os diferentes aspectos que atravessam o processo 
saúde-doença. Para Peduzzi (2001), o modelo biomédico leva-nos a considerar apenas um tipo de atenção à saúde compreendida como pertinente a qualquer situação que se refere ao processo saúde-doença nos planos individuais e coletivos. Entretanto, essa abordagem mostra-se incompatível com a proposta dos cuidados paliativos, que preconiza uma assistência integral ao indivíduo (Figueiredo, 2008). Contudo, outros fatores perpassam a prática do psicólogo em situação de cuidados paliativos como, por exemplo, a falta de capacitação e especialização para lidar com esses pacientes (Arranz, Barbero, Barreto \& Bayés, 2004). Os psicólogos ainda não estão adequadamente formados e não têm incentivo para realizar pesquisas, no âmbito da assistência à saúde, que mostrem aos médicos e outros profissionais a efetividade de suas intervenções (Castro \& Bornholdt, 2004). A inserção do psicólogo no âmbito público hospitalar requer, também, uma reflexão sobre o seu modelo de atuação e sobre a situação do sistema público de saúde no Brasil (Almeida, 2000). Assim, o psicólogo ainda encontra pouco espaço para trabalhar nesse contexto. Observa-se, assim, que uma assistência integral apenas será possível através do reconhecimento e da atuação conjunta das demais disciplinas, no sentido de buscar alternativas que ofereçam maior dignidade no tempo restante de vida do paciente terminal, o que por sua vez mostra sua conformidade com os preceitos humanísticos que regem a filosofia dos cuidados paliativos.

\section{Considerações finais}

A partir das falas dos médicos entrevistados é possível concluir que, apesar de eles observarem o sofrimento psicológico do paciente sob diferentes aspectos, há diversos obstáculos para o atendimento integral ao paciente e à inserção da Psicologia em situação de cuidados paliativos. Nesse sentido, observa-se a necessidade de comunicação efetiva entre médico e paciente, de confiança no médico e de um conhecimento de ambos sobre os potenciais benefícios do atendimento psicológico desses casos. Acredita-se que a consideração dessas necessidades poderá se refletir em maior benefício para o paciente.

O sofrimento do paciente em cuidados paliativos, conforme demonstrado pelos entrevistados, pode ser entendido como um sofrimento total, ou seja, cada sintoma tem relação com todos os demais tipos de sofrimento. Enfatiza-se que essa perspectiva implica que o profissional tenha um olhar amplo sobre o paciente, uma vez que ao cuidar (ou descuidar) de um tipo de sofrimento estará, por conseguinte, cuidando (ou descuidando) de todos os demais. Diante

Tabela 2. Critérios de encaminhamento para a Psicologia

Critérios de encaminhamento para a Psicologia
Negação
Risco de suicídio
Paciente com dificuldades
Depressão
Dificuldade na abordagem de questões legais
Desespero
Resistência ao tratamento
Raiva
Abandono ou superproteção do paciente (família)
Dificuldade de elaboração do luto (família)
Conflitos entre o paciente e familiares
Falta de compreensão (do médico) das questões psicológicas
Famílias difíceis
Apoio para a equipe
Preventivo


disso, destaca-se a necessidade de oferecer um cuidado interdisciplinar ao paciente em cuidados paliativos.

O encaminhamento de pacientes para assistência psicológica depende da sensibilidade do profissional perante o sofrimento manifestado e da forma como valoriza e mostra ao paciente sobre a sua importância. No entanto, os critérios de encaminhamento são basicamente subjetivos, ou seja, da relação que se estabelece entre cada profissional e o paciente. Na realidade, o ideal seria que o psicólogo tivesse autonomia no seu trabalho para ele mesmo fazer o contato com o paciente, juntamente com a equipe, e assim identificar as necessidades do paciente em cuidados paliativos e de sua família. Com isso, o paciente não precisaria ser encaminhado, pois o psicólogo ativo e autônomo na equipe avaliaria e interviria na situação conforme a necessidade, em conjunto com os demais profissionais. No entanto, como a realidade não é essa e os psicólogos nas equipes são insuficientes para fazerem esse tipo de trabalho, propõe-se aqui alguns critérios de encaminhamento para a Psicologia que podem nortear as ações dos profissionais da saúde na atenção ao paciente em cuidados paliativos (Tabela 2).

Para finalizar, considera-se que a partir deste estudo foi possível compreender algumas questões relacionadas às dificuldades na compreensão da e na atuação interdisciplinar, especialmente da área médica, para os pacientes em cuidados paliativos. Entretanto, é necessário aprofundar o tema em futuras pesquisas, tendo em vista que este estudo trata de um tema ainda pouco explorado no Brasil e, portanto, apenas explorou de um ponto de vista qualitativo a percepção de médicos sobre o assunto, não sendo possível generalizar seus achados. 


\section{Elisa Kern de Castro}

Doutora em Psicologia Clínica y de La Salud pelo Universidad Autónoma de Madrid, Universidade do Vale do Rio dos Sinos, São leopoldo - RS. Brasil.

E-mail: elisakc@unisinos.br

\section{Sílvia Menna Barreto}

Graduada em Psicologia pela Universidade do Vale do Rio dos Sinos, São leopoldo - RS. Brasil.

E-mail: silvia.mbarreto@gmail.com

Endereço para envio de correspondência:

Universidade do Vale do Rio dos Sinos. Avenida Unisinos, 950. Cristo Rei.

CEP 93022-000 - São Leopoldo, RS - Brasil.

Recebido 19/11/2012, 1a Reformulação 25/09/2013, Aprovado 16/10/2013. 
Alarcão, A. C., Carvalho, M. D., \& Pelloso, S. M. (2008). A morte de um filho jovem em circunstância violenta: compreendendo a vivência da mãe. Revista Latino-Americana de Enfermagem, 16(3), 341-347. PMid:18695804.

Almeida, E. C. (2000). O psicólogo no hospital geral. Psicologia: Ciência e Profissão, 20(3), 24-27.

Almonacid, V., Moreno, P., \& Lluch, A. (2009). Estudio sobre la derivación de pacientes oncológicos a la unidad de psico-oncología según criterio médico. Psicooncología, 6(1), 203-210.

Arranz, P., Barbero, J., Barreto, P., \& Bayés, R. (2004). Intervención emocional en cuidados paliativos: modelo y protocolos (2. ed.). Barcelona: Ariel.

Böing, E., \& Crepaldi, M. A. (2010). O psicólogo na atenção básica: uma incursão pelas políticas públicas de saúde brasileiras. Psicologia Ciência e Profissão, 30(3), 9-25.

Borges, A. D., Silva, E. F., Toniollo, P. B., Mazer, S. M., Valle, E. R., \& Santos, M. A. (2006). Percepção da morte pelo paciente oncológico ao longo do desenvolvimento. Psicologia em Estudo, 11(2), 361-369. http://dx.doi.org/10.1590/ S1413-73722006000200015.

Castro, E. K., \& Bornholdt, E. (2004). Psicologia da saúde x psicologia hospitalar: definições e possibilidades de inserção profissional. Psicologia, Ciência e Profissão, 24(3), 48-57. http://dx.doi. org/10.1590/S1414-98932004000300007.

Creswell, J. W.(2007) Projeto de Pesquisa: Método qualitativo, quantitativo e misto (2. ed.). Porto Alegre: Artmed.

Diniz, R. W., Gonçalves, M. S., Bensi, C. G., Campos, A. S., Giglio, A. D., Garcia, J. B., et al (2006). O conhecimento do diagnóstico de câncer não leva à depressão em pacientes sob cuidados paliativos. Revista da Associação Médica Brasileira, 52(5), 298-303. http://dx.doi. org/10.1590/S0104-42302006000500014. PMid:17160301

Ferreira, R. A., \& Queiroz, E. (2010). Morte, equipe de saúde e formação profissional: questões para atuação do psicólogo (pp. 101-121). In M. H. P. Franco (Org.), Formação e rompimento de vínculos: o dilema das perdas na atualidade. São Paulo: Summus.

Figueiredo, M. G. M. (2008). Cuidados paliativos. In V. A. Carvalho et al. (Org.), Temas em psicooncologia (pp. 382-387). São Paulo: Summus.
González, R. F., \& Branco, R. (2012). Reflexões sobre o processo ensino-aprendizagem na relação médico-paciente. Revista de Bioética, 20(2), 244-254.

Guimarães, R. (2009). Filosofia dos cuidados paliativos. In E. Saltz \& J. Juver (Orgs.), Cuidados paliativos em oncologia (2. ed., pp. 13-23). Rio de Janeiro: Senac Rio.

Kovács, M. J. (2007). Espiritualidade e psicologia: cuidados compartilhados. Mundo da Saúde, 31(2), 246-255.

Kubler-Ross, E. (2008). Sobre a morte e o morrer (10. ed.). São Paulo: Martins Fontes.

Matos, E., Pires, D. E., \& Campos, G. W. S. (2009). Relações de trabalho em equipes interdisciplinares: contribuições para a constituição de novas formas de organização do trabalho em saúde. Revista Brasileira de Enfermagem, 62(6), 863-869. http://dx.doi. org/10.1590/S0034-71672009000600010. PMid:20098878

Mattos, C. L. (2005). O conselho de classe e a construção do fracasso escolar. Educação e Pesquisa, 31(2), 215-228. http://dx.doi. org/10.1590/S1517-97022005000200005.

Mendes, J. A., Lustosa, M. A., \& Andrade, M. C. (2009). Paciente terminal, família e equipe de saúde. Revista da Sociedade Brasileira de Psicologia Hospitalar, 12(1), 151-173.

Menezes, R. A. (2004). Em busca da boa morte: antropologia dos cuidados paliativos. Rio de Janeiro: Garamond; FIOCRUZ.

Moraes, R. (1999). Análise de conteúdo. Revista Educação, 22(37), 7-32.

Moré, C. L., Crepaldi, M. A., Queiroz, A. H., Wendt, N. C., \& Cardoso, V. S. (2004). As representações sociais do psicólogo entre os residentes do programa de saúde da família e a importância da interdisciplinaridade. Psicologia Hospitalar, 1(1), 59-75.

Nogueira Filho, L. N. (2010). Desafios do médico na manutenção da esperança dos pacientes gravemente enfermos. Revista Brasileira de Saú de Materno Infantil, 10(2), 279-287.

Osanai, M. H. (2004). Relação Médico-Paciente em Oncologia. In D. R. Azevedo, M. C. Barros \& M. C. Müller (Orgs.), Psicooncologia e interdisciplinaridade: uma experiência na 
educação à distância (pp. 239-244). Porto Alegre: Edipucrs.

Peduzzi, M. (2001). Equipe multiprofissional de saúde: conceito e tipologia. Revista de Saude Publica, 35(1), 103-109. http://dx.doi. org/10.1590/S0034-89102001000100016. PMid:11285526

Rezende, V. L. (2000). Reflexões sobre a vida e a morte: abordagem interdisciplinar do paciente terminal. Campinas: Ed. Unicamp.

Riba, J. P., \& Dias, J. J. (2009). Interdisciplinaridade e cuidados paliativos. In E. Saltz \& J. Juver, Cuidados paliativos em oncologia (2. ed., pp. 31-35). Rio de Janeiro: Senac Rio.

Riba, J. P., \& Juver, J. (2009). Como dar as más notícias. In E. Saltz \& J. Juver, Cuidados paliativos em oncologia. (2. ed., pp. 25-30). Rio de Janeiro: Senac Rio.

Salamonde, G. L., Verçosa, N., Barrucand, L., \& Costa, A. F. (2006). Análise clínica e terapêutica dos pacientes oncológicos atendidos no programa de dor e cuidados paliativos do Hospital Universitário Clementino Fraga Filho no ano de 2003. Revista Brasileira de Anestesiologia, 56(6), 602-618. PMid:19468605.

Silva, A. L. (2003). O acompanhamento psicológico a familiares de pacientes oncológicos terminais no cotidiano hospitalar. Interação em Psicologia, 7(1), 27-35.

Silva, G. S., \& Ayres, J. R. (2010). Os estudantes de medicina e o encontro com a morte: dilemas e desafios. In M. H. P. Franco (Org.), Formação e rompimento de vínculos: o dilema das perdas na atualidade (pp. 43-71). São Paulo: Summus.

Silva, R. C., \& Hortale, V. A. (2006). Cuidados paliativos oncológicos: elementos para o debate de diretrizes nesta área. Cadernos de Saude Publica, 22(10), 2055-2066. http://dx.doi. org/10.1590/S0102-311X2006001000011. PMid:16951877

Zibetti, M. L., Souza, F. L., \& Queiroz, K. J. (2010). Quando a escola recorre à psicologia: mecanismos de produção, encaminhamento e atendimento à queixa na alfabetização. Estudos e Pesquisas em Psicologia, 10(2), 490-506. http://dx.doi. org/10.12957/epp.2010.8979. 